\title{
PHYSICOCHEMICAL, PHYTOCHEMICALS AND ANTIOXIDANT EVALUATION OF GUAZUMA ULMIFOLIA FRUIT
}

\author{
BHAVANI DURAISWAMY1, MALAIRAJAN SINGANAN ${ }^{*}$, VANITHA VARADARAJAN ${ }^{3}$
}

\author{
${ }_{1}^{1}$ Research Scholar, PG and Research Department of Chemistry, Presidency College (Autonomous), Chennai 600005, Tamil Nadu, India. \\ ${ }^{2 *} \mathrm{PG}$ and Research Department of Chemistry, Presidency College (Autonomous), Chennai 600005, Tamil Nadu, India. \\ 3Department of Biochemistry, School of Life Sciences, Vels University, Chennai 600117, Tamil Nadu, India \\ *Email: msinganan@yahoo.com
}

Received: 18 Apr 2018 Revised and Accepted: 10 Aug 2018

\begin{abstract}
Objective: The present study was designed to evaluate the physicochemical, qualitative, quantitative analysis and antioxidant activity of ethanol fruit extract of Guazuma ulmifolia. Studies were carried out to detect the bioactive component.

Methods: The physiochemical properties such as loss on drying, extractive value for ethyl acetate, acetone, ethanol, total ash, acid insoluble ash, water-soluble ash and PH values; the phytochemical such as tannins, phenol, terpenoids, flavonoids, saponin, quinones, cardiac glycosides, coumarin, steroids and acids were found using standard methods. The total phenol and flavonoid content were estimated by Folinciocalteu and Aluminium chloride by colorimetric method. In vitro antioxidants, properties were evaluated by DPPH and FRAP assay.

Results: Phytochemical analysis reveals the availability of secondary metabolites like tannins, phenol, terpenoids, flavonoids, coumarin, steroids, and cardiac glycosides in the different extract. The quantitative analysis for ethanolic fruit extract was done for total phenolic content (TPC), total flavonoids content (TFC). An ethanolic extract found to have high TPC [27.2797 \pm 0.1756$]$ than TFC. Antioxidant activity was evaluated by DPPH assay (2, 2-diphenyl-1-picrylhydrazyl-hydrate) and FRAP (ferric Reducing Ability of Plasma).
\end{abstract}

Conclusion: On the basis of this study, it was found that the Guazuma ulmifolia fruits have potential to act as a source of useful drugs due to the presence of various active phytochemical constituent, which will be helpful in preventing various diseases caused by the oxidative stress.

Keywords: Guazuma ulmifolia, Ethanol, Physicochemical, Phytochemical analysis, Antioxidant

(c) 2018 The Authors. Published by Innovare Academic Sciences Pvt Ltd. This is an open access article under the CC BY license (http://creativecommons.org/licenses/by/4.0/) DOI: http://dx.doi.org/10.22159/ijpps.2018v10i9.26778

\section{INTRODUCTION}

Medicinal plants have been a major source of therapeutic agents since ancient times. The curative properties of medicinal plants are due to the presence of various complex chemical substances in different composition [1]. We can promote health and alleviate illness by traditional medicinal plants. According to WHO 2002 report, $80 \%$ of the world population still depends on herbal remedies to cure disease [2]. Such herbal remedies are time-tested, easily available, cheaper and considered safer than some of the modern synthetic drug

The phytochemicals is any of various biologically active compounds found in plants. These biologically active compounds of the plants are steroids, terpenoids, carotenoids, flavonoids, alkaloids, tannins and cardiac glycosides. Plants have a limitless ability to synthesize aromatic substances, mostly flavonoids, phenol or their oxygen-substituted derivatives [3]. Free radicals are produced by our body to stabilize the body's natural function, but the excess amount could cause the cell death and tissue damage. It can also cause oxidative damage to proteins, lipids and DNA, which in turn can cause chronic diseases such as cancer, diabetes, aging, etc., in a human being [4]. These free radicals can be scavenged by the natural and synthetic antioxidant, but antioxidants from natural origin have attracted special interest because they protect the human body from free radicals without any side effect. In the last two decades, there is a fast-growing interest in the plant-based chemical composition of medicine. All over the world, the pharmaceutical industry has made a huge investment in pharmacological and chemical research to discover much more potent drugs.

Guazuma ulmifolia belongs to family Sterculiaceae; it is commonly known as mutamba or Guacimo. It is widely seen in countries such as Caribbean, South America, Mexico, Central America and some parts of India. In India, this can be found at roadsides and wasteland. It was introduced in India more than $100 \mathrm{y}$ ago [5]. Traditionally it has been used as anti-diabetic [6], anti-hypertensive, vaso relaxing
[7], antimicrobial [8], ulcer [9], hair growth promoter, Antisecretonin [10], cytotoxic [11], anthelmintic and hepatoprotective [12]. It is also used as a diuretic and astringent. Rope and twine are manufactured from the tough, fibrous bark and young stem. Due to uniqueness in curing a different ailment, this fruit was selected for the study. The objective of the study was to examine the physicochemicals, qualitative and quantitative analysis and their antioxidant capacity of fruit extract of Guazuma ulmifolia.

\section{MATERIALS AND METHODS}

\section{Chemicals and reagents}

All reagents used in the study were of analytical grade. Folinciocalteu reagent, 2, 2-Diphenyl-1-picrylhydrazyl (DPPH), quercetin, aluminum chloride, ferric chloride, trichloroacetic acid, potassium ferricyanide, 6butylatedhydroxyanisole were purchased from sigma (St. Louis, MO, USA).

\section{Collection and authentication of the plant materials}

Fruits of Guazuma ulmifolia were collected from valluvarkottam, Nungambakkam in Tamil Nadu. The fruits were washed thoroughly with tap water to remove dust particles and another unwanted impurity. Later they were shade dried for 6 to $7 \mathrm{~d}$ and coarsely powdered and separately stored in well-closed bottles for further analysis in the laboratory. The taxonomic identification of the plant material was authenticated by the Plant Anatomy Research Centre, Chennai, India (PARC/2017/3548).

\section{Extraction procedure}

Fruit with the seed of Guazuma ulmifolia was carefully ground and coarsely powdered. The powder was subjected to solvent extraction with petroleum ether, chloroform, ethyl acetate, ethanol and aqueous. The extracts were concentrated by using the rotary evaporator and yield of the extract was collected and stored for future analysis. 


\section{Physicochemical analysis of fruit extract of Guazuma ulmifolia}

The following physicochemical parameters were carried out in dried powder $[13,14]$.

\section{Determination of loss on drying}

Two grams of crude powder of Guazuma ulmifolia fruit were taken in an evaporating dish and dried at $105^{\circ} \mathrm{C}$ in an oven till constant weight was obtained. The dried weight was noted to calculate the loss on drying. The percentage was calculated on the basis of fruit sample taken initially.

$$
\% \text { of loss on drying at } 105^{\circ} \mathrm{C}=\frac{\text { Loss in weight of sample }}{\text { Weight of sample taken }} \times 100
$$

\section{Determination of total ash}

Two grams of dried powder of Guazuma ulmifolia fruit were taken in a silica crucible and heated gradually by increasing the heat to 500 ${ }^{\circ} \mathrm{C}$ and until it turns white, indicating the absence of carbon. Ash was cooled in desiccator and weighed without delay. The $\% \mathrm{w} / \mathrm{w}$ of ash with reference to the air-dried drug.

$$
\% \text { of total ash }=\frac{\text { Weight of ash }}{\text { Weight of teh sample taken }} \times 100
$$

\section{Determination of acid insoluble ash}

$25 \mathrm{ml}$ of hydrochloric acid $(70 \mathrm{~g} / \mathrm{l})$ was added to the crucible containing total ash, covered it with a watch-glass and heated gently for $5 \mathrm{~min}$ to boil, rinse it with $5 \mathrm{ml}$ of hot water and this liquid was added to the crucible. The insoluble matter was collected in an ash less filter paper and washed with hot water till the filter was neutral. Transfer the filter paper containing insoluble to the original crucible matter and dry it on a hot plate and heat till constant weight was obtained. Allowed the residue to cool in a desiccator for $30 \mathrm{~min}$ and then weighed it without delay.

$$
\% \text { acid insoluble ash }=\frac{\text { Weight of acid insoluble residue }}{\text { Weight of teh sample taken }} \times 100
$$

\section{Determination of ethyl acetate soluble extractive value}

Five grams of dried powder of Guazuma ulmifolia fruit were taken in a conical flask, added $100 \mathrm{ml}$ of ethyl acetate, plugged with cotton wool and then kept on a rotary shaker at $120 \mathrm{rpm}$ for $24 \mathrm{~h}$. Pipetted out $25 \mathrm{ml}$ of filtrate in a pre-weighed $100 \mathrm{ml}$ beaker and evaporated to dryness on the water bath, then it was kept in an air oven at 105 ${ }^{\circ} \mathrm{C}$ for $6 \mathrm{~h}$ and in desiccator for $30 \mathrm{~min}$ and weighed.

$\%$ of ethyl acetate soluble extractive

$$
=\frac{\text { Weight of extract }}{25 \text { Xweight of the sample taken }} \times 100
$$

\section{Determination of acetone soluble extractive value}

Five grams of dried powder of Guazuma ulmifolia fruit were taken in a conical flask, added $100 \mathrm{ml}$ of acetone, plugged with cotton wool and then kept on a rotary shaker at $120 \mathrm{rpm}$ for $24 \mathrm{~h}$. Pipetted out $25 \mathrm{ml}$ of filtrate in a pre-weighed $100 \mathrm{ml}$ beaker and evaporated to dryness on the water bath, then it was kept in an air oven at $105^{\circ} \mathrm{C}$ for $6 \mathrm{~h}$ and in a desiccator for $30 \mathrm{~min}$ and weighed.

$\%$ of actetone soluble extractive

$$
=\frac{\text { Weight of extract }}{25 \times \text { weight of the sample taken }} \times 100
$$

\section{Determination of ethanol soluble extractive value}

Five grams of dried powder of Guazuma ulmifolia fruit were added in a conical flask with $100 \mathrm{ml}$ of methanol plugged with cotton wool and then kept on a rotary shaker at $120 \mathrm{rpm}$ for $24 \mathrm{~h}$. Pipetted out $25 \mathrm{ml}$ of filtrate in a pre-weighed $100 \mathrm{ml}$ beaker and evaporated to dryness on the water bath, then it was kept in an air oven at $105{ }^{\circ} \mathrm{C}$ for $6 \mathrm{~h}$ and in a desiccator for $30 \mathrm{~min}$ and weighed.

$\%$ of ethanol soluble extractive

$$
=\frac{\text { Weight of extract }}{25 \times \text { weight of the sample taken }} \times 100
$$

\section{Determination of water-soluble extractive value}

Five grams of dried powder of Guazuma ulmifolia fruit were taken in a conical flask with $100 \mathrm{ml}$ of water plugged with cotton wool and then kept on a rotary shaker at $120 \mathrm{rpm}$ for $24 \mathrm{~h}$. Take $25 \mathrm{ml}$ of filtrate in a pre-weighed $100 \mathrm{ml}$ beaker and evaporated to dryness on the water bath, then it was kept in an air oven at $105^{\circ} \mathrm{C}$ for $6 \mathrm{~h}$ and in desiccators for $30 \mathrm{~min}$ and weighed.

$\%$ of water soluble extractive

$$
=\frac{\text { Weight of extract }}{25 \mathrm{X} \text { weight of the sample taken }} \times 100
$$

\section{Determination of $\mathrm{pH}$ value:}

Dried powder of Guazuma ulmifolia fruit with seed was dissolved in demineralized water and was kept in a water bath for $20 \mathrm{~min}$. It was then filtered and the $\mathrm{pH}$ of the filtrate was noted with the help of the $\mathrm{pH}$ meter.

\section{Qualitative analysis of fruit extract of Guazuma ulmifolia}

The phytochemical test was done by following the standard method [15]. Quantitative analysis of ethanolic extract of Guazuma ulmifolia fruit

\section{Determination of total phenolic content (TPC)}

The Folinciocalteu method was followed to determine the total phenolic content of the fruit extract [16]. Distilled water $(500 \mu \mathrm{l})$ and FolinCiocalteu reagent $(100 \mu \mathrm{l})$ were added to $100 \mu \mathrm{l}$ of the plant extract and incubated for $6 \mathrm{~min}$ at room temperature. The final volume was made up to $3 \mathrm{ml}$ after addition of $1.25 \mathrm{ml}$ of $7 \%$ sodium carbonate. The absorbance was measured at $760 \mathrm{~nm}$ using UVvisible spectrophotometer after an incubation period of $90 \mathrm{~min}$ (mg TAE/g DW).

\section{Determination of total flavonoid content (TFC)}

The TFC of the plant extract was determined by the aluminium chloride colourimetric method [17]. The fruit extract $(200 \mu \mathrm{l})$ was taken in a test tube and the solvent was allowed to evaporate. To the residue, $5 \mathrm{ml}$ of $0.1 \mathrm{M}$ aluminium chloride was added and shaken well. This was followed by incubation for $40 \mathrm{~min}$ at room temperature and the absorbance value was measured at $415 \mathrm{~nm}$ using UV-visible spectrophotometer. A standard plot of quercetin at varying concentrations was used to evaluate the total flavonoid content, expressed as milligrams of quercetin equivalent per gram of dry weight (mg QE/g DW) of the plant material.

In vitro antioxidant analysis of ethanolic fruit extract of Guazuma ulmifolia

\section{2, 2-Diphenyl-1-picrylhydrazyl (DPPH) assay}

Free radical scavenging assay for ethanolic fruit extract of Guazuma ulmifolia was taken at various concentrations $(100,200,300,400$ and $500 \mu \mathrm{l} / \mathrm{ml}$ ) in small tubes and made up to $1 \mathrm{ml}$ using methanol. $1 \mathrm{ml}$ of $0.01 \mathrm{mmol}$ DPPH dissolved in methanol was added to all the test concentrations and maintained in the dark for $30 \mathrm{~min}$, at room temperature. The absorbance of the solutions was read at $517 \mathrm{~nm}$. The percentage inhibition and the IC50 values were calculated with DPPH as the control and butylated hydroxyanisole (BHA) as the reference [18]. The concentration in $\mu \mathrm{g}$ of dry material per $\mathrm{ml}$ of solvent $(\mu \mathrm{g} / \mathrm{ml})$ that inhibits the formation of DPPH radicals by $50 \%$ is defined as IC50 value.

$$
\begin{aligned}
& \% \text { inhibition } \\
& =\frac{\text { Absorbance of the control }(\mathrm{Ac})-\text { Absorbance of the sample }(\mathrm{As})}{\text { Absorbance of the control(Ac) }} \times 100
\end{aligned}
$$

\section{Ferric reducing antioxidant ability (FRAP) assay}

(FRAP) assay $1 \mathrm{ml}$ of ethanolic fruit extract of Guazuma ulmifolia, 2.5 $\mathrm{ml}$ phosphate buffer (of $0.2 \mathrm{M}, \mathrm{pH}$ 7) [19] and 1\% potassium ferricyanide $(2.5 \mathrm{ml})$ were mixed and incubated at $50{ }^{\circ} \mathrm{C}$ for 30 min. To the solution, $2.5 \mathrm{ml}$ of $10 \%$ trichloroacetic acid was added and centrifuged at $6500 \mathrm{rpm}$ for $10 \mathrm{~min}$. Distilled water 
$(2.5 \mathrm{ml})$ and $0.5 \mathrm{ml}$ of $0.1 \% \mathrm{FeCl} 3$ were added to $2.5 \mathrm{ml}$ of the supernatant.

The absorbance of the solution was measured at $700 \mathrm{~nm}$ using UVvisible spectrophotometer. The reducing ability of the plant was evaluated in terms of percentage by relating to the standard, FeSO4.

\section{$\%$ inhibition}

$=\frac{\text { Absorbance of the control }(\mathrm{Ac})-\text { Absorbance of the sample(As) }}{\text { Absorbance of the control }(\mathrm{Ac})} \times 100$

\section{RESULTS}

\section{Guazuma ulmifolia fruit}

Physicochemical analysis values of powder were shown in table 1 . The loss on drying at $105^{\circ} \mathrm{C}$ in fruit was found to be $8.62 \%$. The ash value was determined by three different forms viz. 1 . Total ash, 2. Water soluble ash and 3 . Acid-insoluble ash. The total ash content was found to be $2.25 \%$, water-soluble ash and acid insoluble ash values are $5.2 \%$ and $1.34 \%$ respectively.

Table 1: Physico-chemical evaluations of Guazuma ulmifolia fruit extract

\begin{tabular}{lll}
\hline S. No. & Parameters & Result \\
\hline 1 & Ash (Total ash) & $3.84 \%$ \\
2 & Loss on drying at $105^{\circ} \mathrm{C}$ & $8.62 \%$ \\
3 & Acid-insoluble ash & $1.34 \%$ \\
4 & Water-soluble extractive value & $5.2 \%$ \\
5 & Alcohol Soluble extractive value & $2.62 \%$ \\
6 & Hexane soluble extractive value* & $0.94 \%$ \\
7 & Ethylacetate soluble extractive value* & $1.66 \%$ \\
8 & Acetone soluble extractive value & $1.81 \%$ \\
9 & PH $(10 \%$ aqueous solution) & $5.35 \%$ \\
\hline
\end{tabular}

The phytochemical analysis result given in table 2 reveals the presence of many medicinally important secondary metabolite types of phytoconstituents like cardiac glycosides, tannin, terpenoids, etc., and its presence indicates that the plant possesses high profile values and can be used to treat various kinds of diseases.
The level of TPC and TFC was estimated using standard methods and the result was presented in the table 3.

Table 4 shows the antioxidant value of the ethanolic extract of Guazuma ulmifolia fruit was high for FRAP; the highest antioxidant activity was recorded than the case of DPPH assay.

Table 2: Preliminary phytochemical analysis of fruit extract of Guazuma ulmifolia

\begin{tabular}{|c|c|c|c|c|c|c|}
\hline S. No. & Name of the phytoconstituents & Petroleumether extract & $\begin{array}{l}\text { Chloroform } \\
\text { extract }\end{array}$ & $\begin{array}{l}\text { Ethyl acetate } \\
\text { extract }\end{array}$ & $\begin{array}{l}\text { Ethanol } \\
\text { extract }\end{array}$ & $\begin{array}{l}\text { Aqueous } \\
\text { extract }\end{array}$ \\
\hline 1 & Sterol & + & + & ++ & + & + \\
\hline 2 & Tannin & - & - & ++ & ++ & + \\
\hline 3 & Phenol & - & - & ++ & ++ & + \\
\hline 4 & Terpenoids & + & + & ++ & ++ & - \\
\hline 5 & Flavonoids & - & - & - & - & - \\
\hline 6 & Saponins & - & - & - & - & - \\
\hline 7 & Quinone & - & - & - & + & - \\
\hline 8 & Cardiac glycosides & + & + & +++ & +++ & - \\
\hline 9 & Coumarin & - & - & - & ++ & - \\
\hline 10 & Acid & - & - & - & + & - \\
\hline
\end{tabular}

-: Absent; +: Less present; ++: Moderate present; +++: High present.

Table 3: Quantitative phytochemical analysis in Guazuma ulmifolia fruit extract

\begin{tabular}{ll}
\hline Sample $\mathbf{~ m g} / \mathbf{g}$ & Ethanol extract of Guazuma ulmifolia fruit \\
\hline Total phenol mg TAE/g DW & $27.2797 \pm 0.1756$ \\
Total flavonoids mg QE/g DW & $0.5544 \pm 0.00018$ \\
\hline
\end{tabular}

TAE: Tannic acid equivalent; QE: quercetin equivalent. All measurement were carried out in triplicate, and the values were expressed as mean \pm standard deviation $(\mathrm{n}=3)$.

Table 4: Antioxidant activities of Guazuma ulmifolia determined by DPPH and FRAP

\begin{tabular}{lll}
\hline Concentration $(\boldsymbol{\mu g} / \mathbf{m l})$ & \% Inhibition of DPPH & \% Inhibition of FRAP \\
\hline 100 & 25.29 & 2.86 \\
200 & 26.44 & 11.43 \\
300 & 30.65 & 17.14 \\
400 & 34.48 & 21.43 \\
500 & 42.15 & 40.0 \\
\hline
\end{tabular}

All measurement were carried out in triplicate, and the values were expressed as mean \pm standard deviation $(\mathrm{n}=3)$. 


\section{DISCUSSION}

Physicochemical and phytochemical analysis are useful to evaluate the chemical constituents present in the crude drug and help in the estimation of specific constituents soluble in a particular solvent. This data serves as a valuable source of information, provide appropriate standards to maintain the quality of this plant material in future application. Table2 shows qualitative phytochemical analysis of the five-extract fraction (Petroleum ether, chloroform, ethyl acetate, ethanol, aqueous). The ethanolic fruit extract was found to contain major secondary metabolites. Tannin, terpenoids, coumarin, sterol and cardiac glycoside were excessively present in the ethanolic extract of Guazuma ulmifolia fruit.

The phytochemical investigation gave valuable information about the different phytoconstituents present in the fruit Guazuma ulmifolia, which help us in future regarding the selection of the particular extract for further investigation of isolating the active principle and also gave idea about different phytochemicals that have been found to possess a wide range of activities, which may help in protection against Chronic diseases. For example, alkaloids [20] have antitumor, immune suppressant, insecticidal and antifeedal properties. It also protects against chronic disease. Tannins protect from different diseases, disorders caused by microbial infections and potent free radicals scavenging effect. The biological properties of many plants are due to the phenolic compounds present in them. Phenol serves as plant defense mechanism to counteract reactive oxygen species, responses to ecological pressures such as pathogen and insect attack, UV radiation and wounding organism synthesize phenolic compounds.

A phenolic compound was a very good antioxidant, so possess the wide range of biochemical activity such as antimutagenic, anticarcinogenic, modify the gene expression and also cure various disease related to oxidative stress. The antioxidant activity of a phenolic compound is due to their structure in particular to the number and position of the hydroxyl groups and the nature of the substitutions on the aromatic ring. Flavonoids are great biological response modifier because it goes beyond the yeomen's work of your average antioxidants in curing antihistamine, antimicrobial, memory and even mood-enhancing properties. Flavonoids induce mechanism that kills the cancer cell, inhibit tumor invasion, apart from this show antiallergic, anti-inflammatory, antimicrobial and anticancer [21]. The plants thus find their medicinal values due to the presence of respective phytochemical constituents.

Oxidation reaction can produce free radicals, leading to chain reactions that may damage cells. Free radicals are chemical complex that can exist separately with one or more unpaired electrons, which are unstable and reach out and capture electrons from other substances in order to neutralize themselves. It initially stabilizes the free radical, but another radical is generated by this process. This chain reaction leads to the production of thousands of free radicals within a few seconds. An antioxidant is a molecule that inhibits the oxidation of other molecules. Antioxidants are capable of stabilizing or deactivating free radicals before they attack healthy cell. Phenolic compound free radical scavenging activity is due to their redox properties in absorbing and neutralizing free radicals, quenching singlet and triplet oxygen. DPPH antioxidant effect is due to hydrogen donating ability or radical scavenging activity. When a substance is mixed with DPPH solution, it donates a hydrogen atom and then gets reduced to diphenylpirylhydrazine. DPPH is a stable free radical with red colour. If free radicals have been scavenged, then it will generate its colour to yellow. This character shows the presence of free radical scavenging activity of ethanolic extract of Guazuma ulmifolia fruit.

FRAP is a novel method for assessing antioxidant power as reductants in a redox-linked colorimetric method employing an easily reduced oxidant. The reducing ability of a compound is due to reductants, which exhibit antioxidant potential by breaking the free radical chain with the donated hydrogen atom which reduces ferric tripyridyltrizine from a colorless complex ferrous to 2,4,6-tripyridyls-triazine(blue) that can be monitored by measuring absorbance at $593 \mathrm{~nm}$. The absorption readings are related to the reducing power of the electron donating antioxidants present in the test compound. Hence the FRAP assay can rank the reducing power and antioxidant potential of a wide range of the test compound. The presence of various phytochemicals in the tested plant reveals that this plant may be a good source for production of new drugs for various ailments.

\section{CONCLUSION}

The present study concludes that the Guazuma ulmifolia fruits have potential to act as a source of useful drug due to the presence of various active phytochemical constituent such as cardiac glycosides, Terpenoids, steroids,etc. It also has large amount of phenolic phytoconstituents. The in vitro assay shows that the presence of antioxidant in the ethanolic extract of Guazuma ulmifolia fruit, which will be helpful in preventing various diseases caused by the oxidative stress. However, the responsible for the oxidative activity are not known. Therefore, further investigations are needed for isolation and to identify the antioxidant compound. These plants can be used for further studies to find more about their pharmacological benefits and their potential against fighting various ailments and diseases.

\section{AUTHORS CONTRIBUTIONS}

Experimental work and drafting of the manuscript was done by Bhavani Duraiswamy. The design, guidance of the research work and correction of the manuscript was done by Malairajan Singanan. Part of the laboratory facilities was provided by Vanitha Varadarajan.

\section{CONFLICT OF INTERESTS}

We declare that there were no conflicts of interest

\section{REFERENCES}

1. Shailjasingh, Shalinijaiswal. Therapeutic properties of Ficusreligiosa. Int J Eng Res Gen Sci 2014;2:2691-730.

2. WHO. Quality Control Methods for Medicinals plants, Geneva; 2002. p. 28-31.

3. TS Geisssman. Flavanoid compounds. In: M Florkin, Stotz. Ed. Pyrrolepigments, Isoprenoid. Compounds Phenolic Plant Constituents 1963;9:265.

4. Aiyegoro OA, Okoh AI. Preliminary phytochemical screening and in vitro antioxidant activities of the aqueous extract of Helichrysumlongifolium DC. BMC Complement Altern Med 2010;10:21.

5. Minakshi Sharma, Shrutichopra, Shyambaboo Prasad. Guazumatomentosa: a valuable medicinal plant. Int J Pharmacogn Phytochem Res 2015;7:197-200.

6. Alarcon Aguilara FJ, Roman Ramos R, Perez Gutierrez S, Aguilar contreras A, Contreras Weber CC. Study of the antihyperglycemic effect of the plant used as antidiabetic. J Ethanopharmacol 1998;61:101-10.

7. Magos GA, Mateos JC, Paez E, Fernandez G, Labato C. Hypotensive and vasorelaxant effects of the procyanidin fraction from Guazumaulmifolia bark in normotensive and hypertensive rats. J Ethanopharmacol 2008;117:58-68.

8. Navarro MC, Montilla MP, Cabo MM, Galisteo M, Caceres A. Berger I. Antibacterial, the antiprotozoal and antioxidant activity of five plants used in Izabal for infectious diseases. J Phytother Res 2003;17:325-9.

9. Berenguer B, Trabadela C, Sanchaz Fidalgo S, Quilez A, Mino P. The aerial parts of Guazumaulmifolia lam protect against NSAIDinduced gastric lesions. J Ethanopharmacol 2007;114:153-60.

10. Hoer M, Rimpler H, Heinrich M. Inhibition of intestinal chloride secretion by proanthocyanidins from guazumaulmifolia. J Plant Med 1995;61:208-12.

11. Kashiwada Y. Tannins and related compounds as selective cytotoxic agents. J Nat Prod 1992;55:1033-43.

12. Sharma M, Prasad SB, Yashwant. Hepatoprotective activity of GuazumaTomentosa leaf extracts against CCI 4 induced liver damage in rats. Int J Curr Pharm Rev Res 2013;4:128-38.

13. Vanitha Varadharajan, Umadevi KumbaJanarthanan, Vijayalakshmi Krishnamurthy. Physicochemical, phytochemical screening and profiling of secondary metabolites of annonasquamosa leaf extracts. World J Pharm Res 2012;4:1143-64. 
14. Tyler V. Phytomedicines in Western Europe: their potential impact on herbal medicine in the United States. Herbalgram 1994;30:24-30.

15. Harborne JB. Phytochemical methods. Chapman and Hall Ltd. London: 1973. p. 49-188.

16. McDonald S, Prenzler PD, Autolovich M, Robards K. Phenolic content and antioxidant activity of olive extracts. Food Chem 2001;73:73-84.

17. Chang CC, Yang MH, Wen HM, Chern JC. Estimation of total flavonoid content in propolis by two complementary colorimetric methods. J Food Drug Anal 2002;10:178-82.

18. Vinodhini S, Shripreethi M, Nusrathfathima N, Shivanikushwaha Devi Rajeswari. Antioxidant and free radical scanenging activity of punicagranatun leaf extracts. Asian J Pharm Clin Res 2016;9:140-6.

19. Sukrasno, Slamettuty, Irdafidrianny. Antioxidant evaluation and phytochemical content of various rice bran extracts of three varieties rice from semarang, Central Java, Indonesia. Asian J Pharm Clin Res 2017;10:377-82.

20. Morita $\mathrm{H}$, Sato $\mathrm{Y}$, Chan $\mathrm{KL}$, Choo $\mathrm{CY}$, Itokawa $\mathrm{H}$, Takeya $\mathrm{K}$, et al. A Benzoquinazolinealkaloid from the seeds of Annona Squamosa. J Nat Prod 2000;63:1707-8.

21. Schuier, Maximilian, Helmut Sies, Beatellek, Horst Fischer. Cocoa-related flavonoidsinhibit CFTR-mediated chloride transport across T84 human colon epithelia. J Nutr 2005;135:2320-5. 